\title{
PENGARUH DISIPLIN KERJA DAN IKLIM KOMUNIKASI TERHADAP KINERJA PEGAWAI DINAS PERHUBUNGAN KOTA YOGYAKARTA, DENGAN MOTIVASI KERJA SEBAGAI VARIABEL INTERVENING
}

\author{
Siti Noer Istiqomah \\ Program Magister Manajemen \\ Program Pascasarjana, Fakultas Ekonomi Universitas Islam Indonesia \\ Suhartini \\ Program Magister Manajemen \\ Program Pascasarjana, Fakultas Ekonomi Universitas Islam Indonesia \\ e-mail:903110101@uii.ac.id
}

\begin{abstract}
Good management of human resource will be able to improve the performance of employees based on the expectation of the organization. This study was aimed to determine the effect of working discipline and communication climate towards the employees' performance of the Department of Transportation of Yogyakarta (DPKY), with working motivation as an intervening variable. The research population was all employees of the Transportation Department of Yogyakarta, with the total number of 216 people. The number of samples was 68 people and taken by using a technique of stratified random sampling. The hypothesis testing was using t-test, F, Independent Sample t-test and path analysis. The results showed that: (1) There is a significant influence between working discipline and communication climate towards the working motivation of the employees of DPKY either partially or simultaneously, (2) There is a significant influence between working discipline and communication climate to employee performance DPKY, either partially or simultaneously, (3) There is a significant influence between working motivation towards the employee performance of $D P K Y$, (4) There are differences in performance but it is not significant between employees with civil servant status and non-civil servant status; and (5) The direct effect (working discipline and communication climate towards the performance) is greater than indirect effect (work discipline and communication climate towards the performance through working motivation).
\end{abstract}

Keywords: Working Discipline, Communication Climate, Working Motivation, Performance

\begin{abstract}
Abstrak
Manajemen sumber daya manusia yang baik akan dapat meningkatkan kinerja karyawan berdasarkan harapan organisasi. Penelitian ini bertujuan untuk mengetahui pengaruh disiplin dan iklim komunikasi terhadap kinerja karyawan Departemen Perhubungan Yogyakarta (DPKY) dengan motivasi kerja sebagai variabel intervening. Populasi penelitian adalah seluruh karyawan Dinas Perhubungan Yogyakarta dengan jumlah total 216 orang. Jumlah sampel 68 orang dan teknik pengambilan sampel menggunakan teknik stratified random sampling. Pengujian hipotesis menggunakan t-test, F, Independent Sample t-test dan analisis jalur. Hasil penelitian menunjukkan bahwa: (1) Ada pengaruh yang signifikan antara disiplin kerja dan iklim komunikasi terhadap motivasi kerja karyawan dari DPKY baik secara parsial maupun secara simultan, (2) Ada pengaruh yang signifikan antara disiplin kerja dan iklim komunikasi terhadap kinerja karyawan DPKY, baik secara parsial maupun secara simultan, (3) Ada pengaruh yang signifikan antara motivasi kerja terhadap kinerja karyawan DPKY, (4) Ada perbedaan dalam kinerja tetapi tidak signifikan antara karyawan dengan status PNS dan status non-PNS ; dan (5) Pengaruh langsung (disiplin dan iklim komunikasi ke kinerja) lebih besar dari pengaruh tidak langsung (disiplin kerja dan iklim komunikasi terhadap kinerja melalui motivasi kerja).
\end{abstract}

Kata kunci: Disiplin Kerja, Iklim Komunikasi, Motivasi Kerja, Kinerja 


\section{PENDAHULUAN}

Dalam menghadapi era global, sumber daya manusia memiliki andil besar dalam menentukan kemajuan suatu organisasi. Manajemen kepegawaian menjadi sangat penting bagi organisasi dalam rangka mengelola, mengatur dan memanfaatkan pegawai sehingga dapat berfungsi secara produktif untuk tercapainya tujuan organisasi (Mangkunegara, 2013). Hal ini berlaku baik bagi organisasi swasta maupun pemerintahan. Bagi organisasi pemerintah, manajemen kepegawaian yang efektif dan efisien, diharapkan dapat mewujudkan pelayanan terhadap masyarakat secara tepat, cepat, dan profesional.

Peningkatan kinerja pegawai dalam suatu instansi bukan hal yang mudah. Kinerja karyawan menunjukkan seberapa banyak pegawai memberi kontribusi kepada organisasi, yang diantaranya adalah kualitas output, kuantitas output, kehadiran di tempat kerja dan sikap kooperatif (Jackson dan Mathis, 2002). Kondisi kinerja pegawai Dinas Perhubungan Kota Yogyakarta menunjukkan adanya kinerja yang rendah seperti terlambat datang, pemanfaatan jam kerja yang tidak efektif, penyelesaian tugas tidak tepat waktu dan pulang kerja mendahului jam kerja. Hal ini diduga disebabkan oleh kurangnya disiplin kerja dan tidak terciptanya iklim komunikasi yang baik di lingkungan internal organisasi. Padahal di sisi lain, semakin disiplin seorang pegawai, semakin tinggi prestasi kerja yang dapat dicapai. Tanpa disiplin kerja yang baik, sulit bagi organisasi mencapai hasil yang optimal. Disiplin yang baik mencerminkan besarnya rasa tanggungjawab seorang terhadap tugas-tugas yang diberikan kepadanya (Hasibuan, 2014).

\section{Tujuan Penelitian}

Tujuan penelitian ini adalah: (1) untuk mengetahui pengaruh disiplin kerja dan iklim komunikasi terhadap motivasi kerja pegawai, baik secara parsial maupun simultan, (2) untuk mengetahui pengaruh disiplin kerja dan iklim komunikasi terhadap kinerja pegawai, baik secara parsial maupun simultan, (3) untuk mengetahui pengaruh motivasi kerja terhadap kinerja pegawai, (4) untuk mengetahui ada tidaknya perbedaan kinerja antara pegawai yang berstatus Pegawai Negeri Sipil (PNS) dengan Non PNS dan (5) untuk mengetahui apakah pengaruh langsung (disiplin kerja dan iklim komunikasi terhadap kinerja) lebih besar atau lebih kecil dari pengaruh tidak langsung (disiplin kerja dan iklim komunikasi terhadap kinerja melalui motivasi kerja), dan (5) untuk mengetahui ada tidaknya perbedaan kinerja antara pegawai yang berstatus Pegawai Negeri Sipil (PNS) dengan Non PNS.

\section{KAJIAN PUSTAKA DAN KERANGKA PEMIKIRAN}

\section{Kajian Pustaka}

Disiplin Kerja. Berdasarkan Peraturan Pemerintah Republik Indonesia Nomor 53 Tahun 2010 Tentang Disiplin Pegawai Negeri Sipil, disiplin kerja adalah kesanggupan PNS untuk mentaati kewajibannya dan menghindari larangan yang sudah ditentukan dalam peraturan perundangundanganan dan atau peraturan kedinasan yang apabila tidak ditaati atau dilanggar dijatuhi hukuman disiplin. Disiplin tidak hanya akan meningkatkan perilaku karyawan tetapi juga akan meminimalkan masalah disiplin di masa depan melalui hubungan positif atasan-bawahan (Engelbrecht et al., 2008).

Motivasi Kerja. Motivasi kerja merupakan suatu perangsang keinginan dan daya gerak kemauan yang menciptakan kegairahan seseorang untuk mencapai suatu tujuan yang dikehendaki. Motivasi kerja yang tinggi dari karyawan akan meningkatkan produktivitas perusahaan, sehingga memudahkan pencapaian tujuan perusahaan yang telah ditetapkan (Hartatik, 2014). Motivasi penting karena dengan motivasi ini diharapkan setiap karyawan mau bekerja keras dan antusias untuk mencapai produktivitas kerja yang tinggi (Hasibuan, 2011).

Iklim Komunikasi. Iklim komunikasi organisasi menggambarkan cara orang bereaksi terhadap aspek organisasi. Iklim komunikasi meliputi persepsi-persepsi mengenai pesan dan peristiwa yang berhubungan dengan pesan yang terjadi dalam organisasi (Faules dan Pace, 2013). Iklim komunikasi yang penuh persaudaraan mendorong para anggota organisasi berkomunikasi secara terbuka, rileks, ramah tamah dengan anggota yang lain (Muhammad, 2014).

Kinerja Pegawai. Kinerja merupakan hasil kerja secara kualitas dan kuantitas yang dicapai oleh seorang pegawai dalam melaksanakan tugasnya sesuai dengan tanggung- 
jawab yang diberikan kepadanya (Mangkunegara, 2013).

Penelitian terkait dengan variable penelitian: (1) disiplin kerja berpengaruh positif dan signifikan terhadap motivasi kerja (Binarsih et.al., 2013), (2) variabel disiplin kerja merupakan variabel bebas yang dominan mempengaruhi variabel terkait yaitu kinerja pegawai (Harlie, 2010), (3) motivasi berpengaruh positif dan signifikan terhadap kinerja karyawan (Baskoro, 2014), (4) iklim komunikasi organisasi berpengaruh positif terhadap motivasi kerja. (Filemon, 2013), (5) iklim komunikasi mempunyai pengaruh positif dan signifikan terhadap motivasi kerja (Meilita, 2014), (6) iklim komunikasi organisasi berpengaruh signifikan terhadap produktivitas kerja pegawai (Pangumpia, 2013).

\section{Kerangka Pemikiran}

Kerangka pemikiran pada penelitian ini dapat dilihat pada gambar 1 .

\section{METODE PENELITIAN}

Penelitian ini dilaksanakan di DPKY, Jalan Imogiri No. 1 Yogyakarta. Variabel bebas: disiplin kerja dan iklim komunikasi. Variabel terikat: kinerja pegawai dan variabel intervening: motivasi kerja pegawai.

Definisi Operasional Variabel Penelitian. Kinerja Pegawai: hasil kerja seorang karyawan dalam melaksanakan tugasnya, sesuai dengan tanggungjawab yang diberikan atasan kepada bawahannya, indikatornya: (1) Prestasi Kerja, (2) Kerjasama, dan (3) Ketaatan. Motivasi kerja: semangat untuk melakukan pekerjaan agat tercapai suatu tujuan tertentu. Indikatornya: (1) Moral kerja tinggi, (2) Kepuasan kerja karyawan tinggi, (3) Produktivitas kerja tinggi, (4) Hubungan kerja karyawan baik, (5) Memiliki loyalitas karyawan yang tinggi, (6) Kreatifitas karyawan tinggi, (7) Partisipasi karyawan tinggi, (8) Tingkat kesejahteraan karyawan tinggi, (9) Tanggungjawab karyawan terhadap tugas-tugasnya tinggi dan (10) Efisien dalam penggunaan alat-alat dan bahan baku. Disiplin Kerja: kesanggupan pegawai dalam mentaati kewajiban dan menghindari larangan. Indikator: (1) Hadir setiap hari pada jam dinas, (2) Setiap masuk kerja dan pulang kerja mengisi daftar hadir, (3) Membuat surat izin jika tidak masuk kantor, (4) Setiap keluar pada jam dinas harus izin pimpinan, (5) Mematuhi peraturan di instansi, (6) Bekerja tepat waktu, (7) Bekerja dengan sungguh-sungguh, (8) Tidak pernah menunda-nunda pekerjaan, (9) Mampu bersikap tegas, (10) Berusaha tidak pernah melakukan pelanggaran disiplin. Iklim Komunikasi: proses interaksi timbal balik untuk melakukan pertukaran informasi yang melibatkan unsur-unsur komunikasi, sehingga komunikasi dapat berjalan dengan lancar dan menimbulkan suatu presepsi karyawan terhadap kualitas hubungan dalam suatu organisasi. Indikator: (1) kepercayaan, (2) pembuatan keputusan bersama, (3) kejujuran, (4) keterbukaan dalam komunikasi kebawah, (5) mendengarkan dalam komunikasi keatas, (6) perhatian pada tujuan-tujuan berkinerja tinggi. Jenis data yang dibutuhkan adalah data primer dan sekuder. Data dikumpulkan dengan menggunakan kuesioner dengan skala likert, 14. Instrumen penelitian ini diuji validitas dan reliabilitas sebelum digunakan. Hasil uji validitas: variabel disiplin kerja (11 item), iklim komunikasi (14 item), motivasi kerja (10 item) dan kinerja pegawai (3 item), memiliki nilai signifikan sig. $>0,235$, atau dengan kata lain valid.

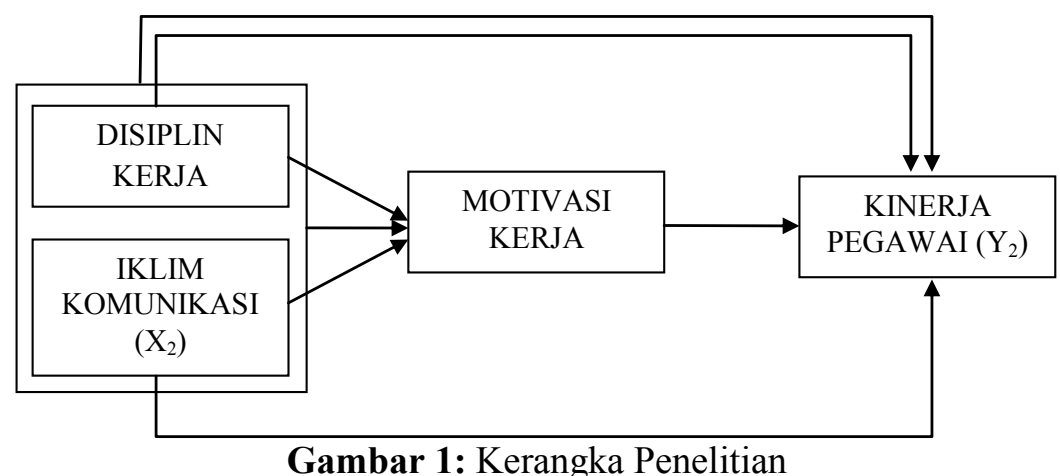

Gambar 1: Kerangka Penelitian 
Tabel 1: Hasil Uji Reliabilitas

\begin{tabular}{lccc}
\hline \multicolumn{1}{c}{ Variabel } & Cronbach Alpha & Nilai Kritis & Keterangan \\
\hline Disiplin Kerja & 0,922 & 0,60 & Reliabel \\
Iklim Komunikasi & 0,938 & 0,60 & Reliabel \\
Motivasi Kerja & 0,938 & 0,60 & Reliabel \\
Kinerja Pegawai & 0,952 & 0,60 & Reliabel \\
\hline
\end{tabular}

Sumber: Data Primer Diolah, 2015.

Tabel 2: Distribusi Sampel

\begin{tabular}{clccc}
\hline No & \multicolumn{1}{c}{ Uraian } & Jumlah & $\begin{array}{c}\text { Prosentase } \\
(30 \%)\end{array}$ & $\begin{array}{c}\text { Pembulatan } \\
\text { Sampel }\end{array}$ \\
\hline 1 & Kepala Dinas & 1 & 0.30 & 0 \\
2 & Sekretariat & 24 & 7.20 & 8 \\
3 & Bidang Lalu Lintas dan Angkutan & 17 & 5.10 & 6 \\
4 & Bidang Pengendalian Operasional dan Bimbingan & 23 & 6.90 & 7 \\
5 & Keselamatan & 15 & 4.50 & 5 \\
6 & Bidang Pengelolaan Perparkiran & 122 & 36.60 & 37 \\
7 & UPT Pengelolaan Terminal & 14 & 4.20 & 5 \\
& & 216 & 64.8 & 68 \\
\hline
\end{tabular}

Sumber: Data Sim pegawai Dinas Perhubungan Kota Yogyakarta (Januari 2015)

Populasi dalam penelitian ini adalah pegawai di jajaran DPKY, yang secara keseluruhan berjumlah 216 orang. Sampel diambil berdasarkan pendapat Arikunto (2013), yang menyatakan bahwa jika peneliti mempunyai beberapa ratus subyek dalam populasi, mereka dapat menentukan kurang lebih $25-30 \%$ dari jumlah subyek tersebut. Oleh karena itu, dalam penelitian ini jumlah sampel ditetapkan yaitu $30 \%$ dari jumlah populasi 216 orang pegawai, yaitu 68 orang (pembulatan). Teknik pengambilan sampel yang digunakan adalah menggunakan Stratified Random Sampling.

Metode analisis yang digunakan: uji t, uji F, Independent Sample $t$ Test dan analisis jalur (Path Analysis).

\section{HASIL DAN PEMBAHASAN}

\section{Analisis Deskriptif}

Dalam penelitian ini disebarkan 68 kuesioner kepada 68 responden. Kuesioner yang kembali sebanyak 68 eksemplar (response rate $100 \%$ ). Kuesioner yang lengkap dan layak dianalisis sebanyak 68 kuesioner.
Tabel 3: Data Karakteristik Responden

\begin{tabular}{cccc}
\hline No & Umur & Jumlah & Persentase \\
\hline 1 & $25-30$ th & 7 & $10,3 \%$ \\
2 & $31-35$ th & 19 & $27,9 \%$ \\
3 & $36-40$ th & 10 & $14,7 \%$ \\
4 & $41-45$ th & 11 & $16,2 \%$ \\
5 & $>45$ th & 21 & $30,9 \%$ \\
& & $\mathbf{6 8}$ & \\
No & Pendidikan & Jumlah & Persentase \\
1 & SD & 4 & $5,9 \%$ \\
2 & SLTP & 2 & $2,9 \%$ \\
3 & SLTA/SMK & 28 & $41,2 \%$ \\
4 & Diploma & 10 & $14,7 \%$ \\
5 & S1/S2 & 24 & $35,3 \%$ \\
& & $\mathbf{6 8}$ & \\
No & Status & Jumlah & Persentase \\
1 & Belum Menikah & 4 & $5,9 \%$ \\
2 & Menikah & 63 & $92,6 \%$ \\
3 & Duda & 1 & $1,5 \%$ \\
& & $\mathbf{6 8}$ & \\
No & Masa Kerja & Jumlah & Persentase \\
1 & 1-5 tahun & 6 & $8,8 \%$ \\
2 & 6-10 tahun & 35 & $51,5 \%$ \\
3 & $>10$ tahun & 27 & $39,7 \%$ \\
& & $\mathbf{6 8}$ & \\
\hline
\end{tabular}

Sumber: Data Primer, Diolah, 2015. 
Peran sumberdaya manusia pada masa kini menjadi penentu bagi keberhasilan sebuah aktifitas yang dilakukan dalam suatu organisasi, baik organisasi swasta atau perusahaan, BUMN maupun instansi pemerintah, (Arikunto, 1996 dalam Supriyanto, dkk., 2013). Tabel 3 menunjukkan bahwa:

1) Berdasarkan karakteristik umur, $51 \%$ Pegawai DPKY adalah usia dewasa akhir. Semakin cukup umur, tingkat kematangan dan kekuatan seseorang akan lebih matang dalam berfikir dan bekerja. Semakin cukup umur, maka tingkat kematangan dan kekuatan seseorang akan lebih matang dalam berpikir dan bekerja yang dapat bedampak pada kinerjanya (Hurlock, 1999).

2) Berdasarkan karakteristik tingkat pendidikan, $81,2 \%$ Pegawai DPKY minimal mempunyai pendidikan tingkat menengah $(\mathrm{SMA} / \mathrm{K})$. Semakin tinggi tingkat pendidikan seseorang, maka dia dapat melakukan sesuatu, misalnya bekerja, sehingga berdampak pada kinerjanya (Notoatmodjo, 2012).

3) Berdasarkan karakteristik status perkawinan, 94,1\% Pegawai DPKY sudah menikah. Status perkawinan berpengaruh terhadap perilaku seseorang dalam kehidupan organisasi baik secara positif maupun negatif (Siagian, 1995)

4) Berdasarkan karakteristik masa kerja, $91,2 \%$ Pegawai DPKY telah bekerja minimal 5 tahun. Semakin lama seseorang bekerja dalam suatu organisasi, maka semakin tinggi motivasi yang berdampak pada kinerjanya (Siagian, 1995).

Tabel 4: Rangkuman Persepsi Responden Terhadap Variabel Penelitian

\begin{tabular}{lcc}
\hline Variabel & Mean & Kategori \\
\hline Disiplin Kerja & 3,25 & Sangat Tinggi \\
Iklim Komunikasi & 3,12 & Kondusif \\
Motivasi Kerja & 3,13 & Tinggi \\
Kinerja Pegawai & 3,70 & Sangat Tinggi \\
\hline
\end{tabular}

Sumber: Data Primer Diolah, 2015.

Disiplin kerja memiliki rerata $\mathbf{3 . 2 5}$ (sangat tinggi). Hal ini menunjukkan bahwa pegawai DPKY memiliki disiplin kerja yang sangat tinggi, dengan datang dan pulang tepat waktu, ijin jika tidak masuk kantor, patuh terhadap aturan yang ada, bertanggungjawab dalam pelaksanaan tugas dan tidak menundanunda pekerjaan. Disiplin yang baik mencerminkan besarnya rasa tanggungjawab seorang terhadap tugas-tugas yang diberikan kepadanya (Hasibuan, 2014).

Iklim Komunikasi memiliki rerata 3.12 (Kondusif). Hal ini menunjukkan bahwa iklim komunikasi di DPKY kondusif, ditunjukkan dengan adanya tingginya saling kepercayaan antara pegawai dengan pimpinan dan sebaliknya. Komunikasi merupakan unsur yang penting dalam kehidupan organisasi, baik ditinjau dari segi proses administrasi dan manajemen maupun keterlibatan semua pihak didalam suatu organisasi (Siagian, 1993 dalam Chairunnisah, 2012).

Motivasi Kerja memiliki rerata $\mathbf{3 . 1 3}$ (Tinggi). Hal ini menunjukkan bahwa karyawan memiliki moral kerja tinggi, puas, produktivitas kerja tinggi dan selalu mempertahankan stabilitas di lingkungan kerja. Prinsip dasar manajemen menyatakan bahwa kinerja sumber daya manusia merupakan perpaduan antara motivasi yang ada pada diri seseorang dan kemampuannya dalam melaksanakan suatu pekerjaan (Feldman, 1998 dalam Widodo, 2009).

Kinerja Pegawai memiliki rerata 3.70 (Sangat Tinggi). Hal ini menunjukkan bahwa prestasi kerja, kerjasama, dan ketaatan pegawai DPKY adalah sangat tinggi.

Hasil uji asumsi klasik, menunjukkan bahwa: (1) Uji Normalitas. Berdasarkan hasil uji normalitas dengan Kolmogorov Smirnov Test menunjukkan bahwa nilai probabilitas $=$ 0,063 dan $0,273>0,05$, maka model regresi memenuhi asumsi normalitas, (2) Uji Multikolinearitas. Berdasarkan hasil uji multikolinearitas dengan metode $\mathrm{VIF}$, nilai $\mathrm{VIF}<10$, artinya bahwa semua variabel bebas tidak terjadi multikolinearitas, sehingga tidak membiaskan interprestasi hasil analisis regresi dan (3) Uji Heteroskedastisitas. Berdasarkan hasil uji heteroskedastisitas dengan menggunakan Glejser terlihat bahwa nilai probabilitas $>0,05$. Hal ini berarti model yang diestimasi bebas dari heteroskedastisitas.

Pengaruh disiplin kerja terhadap motivasi kerja. Hasil analisis regresi menunjukkan bahwa variabel disiplin kerja mempunyai pengaruh signifikan terhadap motivasi kerja Pegawai DPKY (nilai probabilitas $t_{\text {-hitung }}$ $(0,000)<$ Level of Significant $(0,05))$. Hasil penelitian ini didukung penelitian Binarsih, et al (2013) yang menunjukkan bahwa disiplin kerja berpengaruh positif dan signifikan terhadap motivasi kerja pegawai. 
Tabel 5. Hasil Uji Hipotesis

\begin{tabular}{cll}
\hline No & \multicolumn{1}{c}{ Hipotesis } & Keterangan \\
\hline 1 & $\begin{array}{l}\text { Disiplin kerja dan iklim komunikasi mempunyai pengaruh terhadap Motivasi } \\
\text { Kerja pegawai DPKY, baik secara parsial maupun simultan }\end{array}$ & Terbukti \\
2 & $\begin{array}{l}\text { Disiplin kerja dan iklim komunikasi mempunyai pengaruh terhadap Kinerja } \\
\text { pegawai DPKY, baik secara parsial maupun simultan }\end{array}$ & Terbukti \\
3 & $\begin{array}{l}\text { Motivasi kerja mempunyai pengaruh terhadap Kinerja pegawai DPKY } \\
\text { Terdapat perbedaan kinerja antara pegawai berstatus PNS dengan pegawai }\end{array}$ & Terbukti \\
berstatus Non PNS & Terbukti \\
\hline
\end{tabular}

Sumber: Data Primer yang Diolah (2015)

Pengaruh Iklim Komunikasi terhadap Motivasi Kerja. Hasil analisis regresi menunjukkan bahwa variabel iklim komunikasi mempunyai pengaruh signifikan terhadap motivasi kerja Pegawai DPKY (nilai probabilitas t hitung $(0,002)<$ Level of Significant $(0,05))$. Hasil penelitian ini didukung oleh (1) Penelitian Filemon (2013) yang menunjukkan bahwa iklim komunikasi organisasi berpengaruh positif terhadap motivasi kerja dan (2) Penelitian Meilita (2014), yang menunjukkan bahwa iklim komunikasi mempunyai pengaruh positif dan signifikan terhadap motivasi kerja dan (3) Penelitian Sumartono, dkk. (2011) yang menunjukkan bahwa iklim komunikasi mempengaruhi motivasi kerja karyawan dalam kategori tinggi.

Pengaruh Disiplin Kerja dan Iklim Komunikasi terhadap Motivasi Kerja. Hasil analisis regresi menunjukkan bahwa diperoleh nilai probabilitas $\mathrm{F}_{\text {-hitung }}(0,000)<$ Level of Significant $(0,05)$. Hasil penelitian ini juga mendukung hasil penelitian ini didukung oleh penelitian Binarsih dll. (2013) yang menunjukkan bahwa disiplin kerja dan komunikasi berpengaruh secara simultan terhadap motivasi kerja pegawai.

Pengaruh Disiplin Kerja terhadap Kinerja Pegawai. Hasil analisis regresi menunjukkan bahwa variabel disiplin kerja mempunyai pengaruh signifikan terhadap kinerja pegawai DPKY (nilai probabilitas $\mathrm{t}_{\text {-hitung }}$ $(0,001)<$ Level of Significant $(0,05))$. Hasil penelitian ini didukung oleh: (1) Penelitian Baskoro (2014) yang menunjukkan bahwa disiplin kerja berpengaruh positif dan signifikan terhadap kinerja karyawan, (2) Penelitian Harlie (2010), yang menunjukkan bahwa disiplin kerja memiliki korelasi parsial tertinggi mempengaruhi variabel terkait yaitu kinerja pegawai, (3) Penelitian Narmodo dan Wajdi (2004) yang menunjukkan bahwa disiplin kerja mempunyai pengaruh positif yang dominan terhadap kinerja pegawai dan (4) Penelitian Chirasha (2013) yang menunjukkan bahwa disiplin kerja sangat berpengaruh penting terhadap kinerja karyawan.

Pengaruh Iklim Komunikasi terhadap Kinerja Pegawai. Hasil analisis regresi menunjukkan bahwa variabel iklim komunikasi mempunyai pengaruh signifikan terhadap kinerja pegawai DPKY (nilai probabilitas $t_{\text {-hitung }}$ $(0,039)<$ Level of Significant $(0,05))$. Hasil penelitian ini didukung oleh penelitian Pangumpia (2013) yang menunjukkan bahwa iklim komunikasi organisasi berpengaruh signifikan terhadap produktivitas kerja pegawai

Pengaruh Disiplin Kerja dan Iklim Komunikasi terhadap Kinerja Pegawai. Hasil analisis regresi menunjukkan bahwa nilai probabilitas $\mathrm{F}_{\text {-hitung }}(0,000)<$ Level of Significant $(0,05)$, maka disimpulkan bahwa disiplin kerja dan iklim komunikasi berpengaruh secara simultan terhadap kinerja pegawai DPKY. Hasil penelitian ini didukung: (1) Penelitian Narmodo dan Wajdi (2004) yang menunjukkan bahwa disiplin kerja dan iklim komunikasi mempunyai pengaruh secara simultan terhadap kinerja pegawai, (2) Penelitian Hasana (2011) yang menunjukkan bahwa terdapat hubungan antara disiplin kerja dan iklim komunikasi secara simultan dengan kinerja pegawai, (3) penelitian Netra dan Prabasari (2013) menunjukkan bahwa disiplin kerja dan komunikasi secara simultan berpengaruh signifikan terhadap kinerja karyawan. Oleh karena itu, untuk meningkatkan kinerja karyawan perlu didukung oleh komunikasi yang baik dan disiplin kerja yang tinggi.

Pengaruh Motivasi Kerja terhadap Kinerja Pegawai. Hasil analisis regresi menunjukkan bahwa variabel motivasi kerja mempunyai pengaruh signifikan terhadap kinerja pegawai DPKY (nilai probabilitas $t_{\text {-hitung }}$ 
$(0,027)<$ Level of Significant $(0,05))$. Hasil penelitian ini didukung oleh: (1) penelitian Baskoro (2014) yang menunjukkan bahwa motivasi berpengaruh positif dan signifikan terhadap kinerja karyawan, (2) penelitian Harlie (2010) yang menunjukkan bahwa motivasi kerja memiliki korelasi parsial mempengaruhi variabel terkait yaitu kinerja pegawai, (3) penelitian Narmodo dan Wajdi (2004) yang menunjukkan bahwa motivasi kerja mempunyai pengaruh positif terhadap kinerja pegawai, (4) penelititian Ariefiantoro dan Octaviana (2012) yang menunjukkan bahwa motivasi kerja berpengaruh positif terhadap kinerja pegawai, sehingga jika motivasi kerja tinggi maka akan dapat meningkatkan kinerja karyawan.

Perbedaan kinerja antara pegawai berstatus PNS dengan pegawai berstatus Non PNS. Hasil uji perbedaan menunjukkan bahwa nilai probabilitas $\mathrm{t}_{\text {-hitung }}$ variabel kinerja pegawai $=0,078>$ Level of Significant $=0,05$, maka disimpulkan bahwa terdapat perbedaan, tetapi tidak signifikan kinerja antara pegawai berstatus PNS dengan pegawai berstatus Non PNS. Hal ini disebabkan oleh: (1) Gaji yang diterima PNS diatur berdasarkan golongan dan masa kerja, sedangkan gaji yang diterima Non PNS diperhitungkan berdasarkan Upah Minimum Kota dan (2) Status Kepegawaiannya adalah PNS berstatus pegawai tetap, sedangkan Non PNS berstatus pegawai dengan Perjanjian
Kerja, yaitu pelaksanaannya dalam satu tahun dilaksanakan perpanjangan Perjanjian Kerja.

\section{Analisis Jalur}

Gambar 2. Pengaruh langsung (Disiplin Kerja dan Iklim Komunikasi terhadap kinerja pegawai) lebih besar dibandingkan pengaruh tidak langsung (Disiplin Kerja dan Iklim Komunikasi terhadap kinerja pegawai melalui motivasi kerja).

\section{KESIMPULAN}

a. Terdapat pengaruh signifikan antara disiplin kerja dan iklim komunikasi terhadap motivasi Kerja pegawai DPKY, baik secara parsial maupun simultan.

b. Terdapat pengaruh signifikan antara disiplin kerja dan iklim komunikasi terhadap kinerja pegawai DPKY, baik secara parsial maupun simultan.

c. Terdapat pengaruh signifikan antara motivasi kerja terhadap kinerja pegawai DPKY.

d. Terdapat perbedaan kinerja tetapi tidak signifikan antara pegawai berstatus PNS dengan non PNS

e. Pengaruh langsung (disiplin kerja dan iklim komunikasi terhadap kinerja) lebih besar dibandingkan pengaruh tidak langsung (disiplin kerja dan iklim komunikasi terhadap kinerja melalui motivasi kerja)

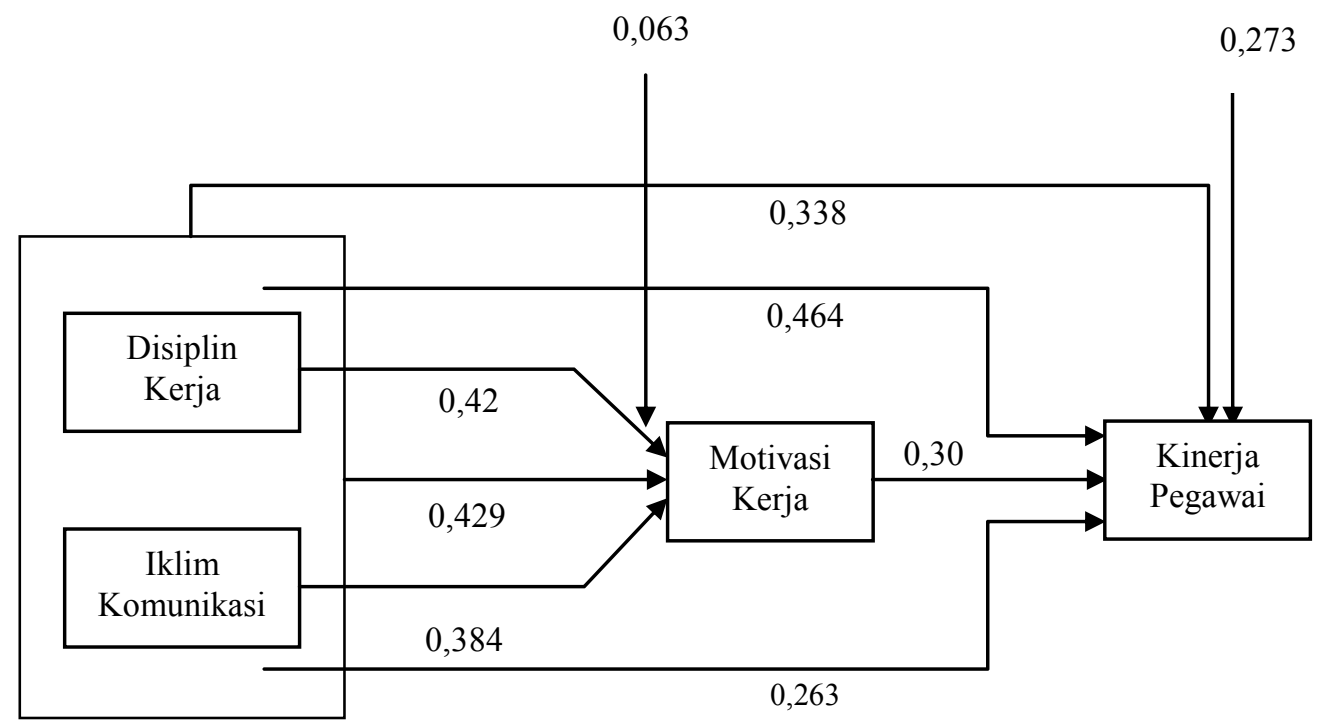

Gambar 2. Analisis Jalur 


\section{DAFTAR PUSTAKA}

Ariefiantoro, Teguh. dan O.S. Kesatria. 2012. Pengaruh motivasi kerja, kepemimpinan, dan lingkungan kerja terhadap kinerja karyawan (studi kasus pada karyawan kontraktor PT Wineh Pandanwangi Semarang. Jurnal Dinamika Manajemen, Vol. 1, No. 3, 82-92.

Arikunto, Suharsimi. 2013. Manajemen Penelitian. Penerbit Rinaka Cipta, Jakarta, Cetakan XII.

Baskoro, Candra Aji. 2012. Pengaruh kepemimpinan transformasional, motivasi dan disiplin kerja terhadap kinerja karyawan. Management Analysis Journal, Vol. 3, No. 2, 1-12.

Binarsih, Siti Rahayu., Istiatin, dan W. Setyawati. 2013. Pengaruh kepemimpinan, disiplin kerja dan komunikasi terhadap motivasi kerja pegawai badan kepegawaian daerah kota Surakarta. Manajemen Bisnis Syariah, No: 02,Th.VI, 1205-1220.

Chairunnisah, Siti. 2012. Pengaruh gaya kepemimpinan, komunikasi internal, dan motivasi kerja terhadap kinerja pegawai. (Studi Kasus Di Kantor Kecamatan Grogol Petamburan Jakarta Barat)", e-Jurnal Ekonomi Universitas Gunadarma, 151-160.

Chirasha, Vonai. 2013. Management of discipline for good performance: a theoretical perspective, Online Journal of Social Sciences Research, ISSN 2277-0844, Volume 2, Issue 7, 214-219.

Engelbrecht, Amos S., S. Johanita. and V.D.B. Louis. 2008. Perceived fairness of disciplinary procedures in the public service sector: an exploratory study, $S A$ Journal of Human Resource Management, Vol. 6, No. 2, $1-8$.

Faules, Don F., dan Pace R. Wayne. 2013. Komunikasi Organisasi. Penerbit PT Remaja Rosdakarya, Bandung, Cetakan ke delapan.

Filemon, Raymond Soelistiono. 2013. Pengaruh iklim komunikasi organisasi terhadap motivasi kerja karyawan PT.
PLN (Persero) Area Sidoarjo. Skripsi, Universitas Diponegoro, Semarang, 1 12.

Hurlock, B Elizabeth. 1999. Psikologi Perkembangan. Jakarta PT Gramedia.

Harlie, M. 2010. Pengaruh disiplin kerja, motivasi kerja dan pengembangan karier terhadap kinerja pegawai negeri sipil pada pemerintah Kabupaten Tabalong di Tanjung Kalimantan Selatan. Jurnal Manajemen dan Akuntansi, Volume 11, Nomor 2, 860-867.

Hartatik, Indah Puji. 2014. Mengembangkan SDM, Penerbit Laksana, Yogyakarta, Cetakan Pertama.

Hasana, Mia Aulia. 2011. Hubungan iklim komunikasi organisasi dengan kinerja pegawai madrasah aliyah negeri (man) suruh kab. Semarang. Skripsi, Universitas Diponegoro, 1-16.

Hasibuan, Malayu SP. 2011. Manajemen Dasar, Pengertian dan Masalah, Penerbit PT Bumi Aksara, Jakarta, Cetakan Ke Sembilan.

Jackson, John H., dan Mathis, Robert L. 2002. Manajemen Sumber Daya Manusia, Human Resource Management, Penerbit Salemba Empat, Jakarta, Buku 2.

Mangkunegara, Anwar Prabu. 2013. Manajemen Sumberdaya Manusia Perusahaan. Penerbit PT Remaja Rosdakarya, Bandung, Cetakan ke sebelas.

Meilita, Mery. 2014. Pengaruh iklim komunikasi dan kepuasan kerja karyawan terhadap motivasi kerja karyawan (studi kasus pada karyawan bagian transaksienergi PT. PLN (Persero) Wilayah Kalimantan Barat Area Sanggau, Jurnal Ilmu Komunikasi, 1-14.

Muhammad, Arni. 2014. Komunikasi Organisasi, Penerbit PT Bumi Aksara, Jakarta, Cetakan 13.

Narmodo, Hernowo., dan Wajdi, M. Farid. 2004. Pengaruh motivasi dan disiplin terhadap kinerja pegawai badan kepegawaian daerah kabupaten Wonogiri. Jurnal Daya Saing, Vol. 5, No. 2, 1-64. 
Netra, I.G. Salit Ketut dan I.G.A.A. Prabasari. 2013. Pengaruh motivasi, disiplin kerja dan komunikasi terhadap kinerja karyawan pada PT PLN (Persero) Distribusi Bali”. Jurnal Manajemen Universitas Udayana, Vol 2, No 4, 469-481.

Notoatmodjo. 2012. Ilmu Perilaku, Jakarta: RinekaCipta.

Pangumpia, Fadly. 2013. Pengaruh iklim komunikasi organisasi terhadap produktivitas kerja karyawan di Bank Prisma Dana Manado, Journal Acta Diurna, Vol II / No. 2.

Peraturan Pemerintah Republik Indonesia Nomor 53 Tahun 2010 Tentang Disiplin Pegawai Negeri Sipil.

Siagian, Sondang. 1995. Teori Motivasi dan Aplikasinya, PT Rineka Cipta, Jakarta.
Sumartono dan T. Esti. 2011. Hubungan antara iklim komunikasi dengan motivasi kerja karyawan PT Astra International Nissan Diesel. Jurnal Komukologi, Volume 8, Nomor 2, 103-126.

Supriyanto, Sapto., Hamzah, Djabir., Kadir, Abdul Rahman. 2013. Pengaruh karakteristik individu dan karakteristik organisasi terhadap motivasi kerja dan kinerja karyawan departemen engineering technical development \& support PT. Vale Indonesia Tbk. Jurnal Magister Manajemen Universitas Hasanuddin, Makassar, 1 - 12.

Widodo. 2009. Upaya peningkatan kinerja sumber daya manusia melalui komitmen dan oreintasi belajar. Media Ekonomi, Vol. 9, No 1, 1-30. 